\title{
Costs associated with the management of waste from healthcare facilities: An analysis at national and site level
}

Waste Management \& Research 2018, Vol. 36(1) 39-47 (c) The Author(s) 2017 Reprints and permissions: sagepub.co.uk/journalsPermissions.nav DOI: 10.1177/0734242X17739968 journals.sagepub.com/home/wmr (SSAGE

\author{
Mentore Vaccari' ${ }^{1}$, Terry Tudor $^{2}$ and Andrea Perteghella ${ }^{1}$
}

\begin{abstract}
Given rising spend on the provision of healthcare services, the sustainable management of waste from healthcare facilities is increasingly becoming a focus as a means of reducing public health risks and financial costs. Using data on per capita healthcare spend at the national level, as well as a case study of a hospital in Italy, this study examined the relationship between trends in waste generation and the associated costs of managing the waste. At the national level, healthcare spend as a percentage of gross domestic product positively correlated with waste arisings. At the site level, waste generation and type were linked to department type and clinical performance, with the top three highest generating departments of hazardous healthcare waste being anaesthetics $\left(5.96 \mathrm{~kg} \mathrm{day}^{-1} \mathrm{bed}^{-1}\right)$, paediatric and intensive care $\left(3.37 \mathrm{~kg} \mathrm{day}^{-1} \mathrm{bed}^{-1}\right)$ and gastroenterology-digestive endoscopy $\left(3.09 \mathrm{~kg} \mathrm{day}^{-1} \mathrm{bed}^{-1}\right)$. Annual overall waste management costs were \$US5,079,191, or approximately $\$$ US2.36 kg-1, with the management of the hazardous fraction of the waste being highest at $\$$ US3,707,939. In Italy, reduction in both waste arisings and the associated costs could be realised through various means, including improved waste segregation, and linking the TARI tax to waste generation.
\end{abstract}

\section{Keywords}

Gross domestic product, healthcare waste costs, Italy, medical waste generation, waste segregation

Received 10th February 2017, accepted 9th October 2017 by Associate Editor Alberto Bezama.

\section{Introduction}

The global financial costs associated with the provision of healthcare services are significant and growing. For example, as illustrated in Figure 1, the percentage spend of gross domestic product (GDP) on healthcare in one of the largest countries (the United States of America (USA)), accounted for around $17.4 \%$ of its' entire GDP in 2014. This figure was up from around $15.3 \%$ in 2006 (World Bank, 2016). While the rates globally and across the Organisation for Economic Cooperation and Development (OECD) countries are lower, and have slowed since the 2008 financial crisis, they are nevertheless generally rising. In Italy, however, where this study was undertaken, it has decreased marginally since 2009 , falling from $9.4 \%$ in 2009 , to $9.2 \%$ in 2014 .

In providing these services, healthcare facilities produce waste. The majority of the waste generated is non-hazardous and is similar to that from households, with only a small percentage being potentially hazardous (World Health Organization, 2011). However, the potential presence of hazards, such as infections, sharps and chemicals, can pose significant risks and lead to higher costs (World Health Organization, 2014). For example, there has been an increasing shift in many developed countries towards the use of disposable and single-use medical items as a means of addressing concerns about the risks of infections (Nichols et al., 2016; World Bank, 2016). At the same time, there is evidence that this shift can lead to increased financial costs (Campion et al., 2015; Swensen et al., 2011; Viani et al., 2016).

Given the potential risks to public health and the environment, there has been an increasing focus on identifying suitable approaches (e.g. effective segregation of hazardous and non-hazardous waste), as a means not only of reducing these risks, but also the costs associated with managing the waste (Castellani et al., 2015; Ibbotson et al., 2013; Mosquera et al., 2014; Windfeld and Brooks, 2015). For example, in the United Kingdom (UK), a $20 \%$ reduction in hazardous healthcare waste $(\mathrm{HCW})$ was estimated to produce savings of approximately \$US11.8 million (Royal College of Nursing, 2011).

This study therefore sought to understand the nature of the relationship between generation patterns of $\mathrm{HCW}$ and the associate

${ }^{1}$ Department of Civil, Environmental, Architectural Engineering and Mathematics, University of Brescia, Brescia, Italy

${ }^{2}$ The School of Science and Technology, University of Northampton. Northampton, UK

\section{Corresponding author:}

Mentore Vaccari, Department of Civil, Environmental, Architectural Engineering and Mathematics, University of Brescia, via Branze 43, 25123 Brescia, Italy.

Email: mentore.vaccaridunibs.it 


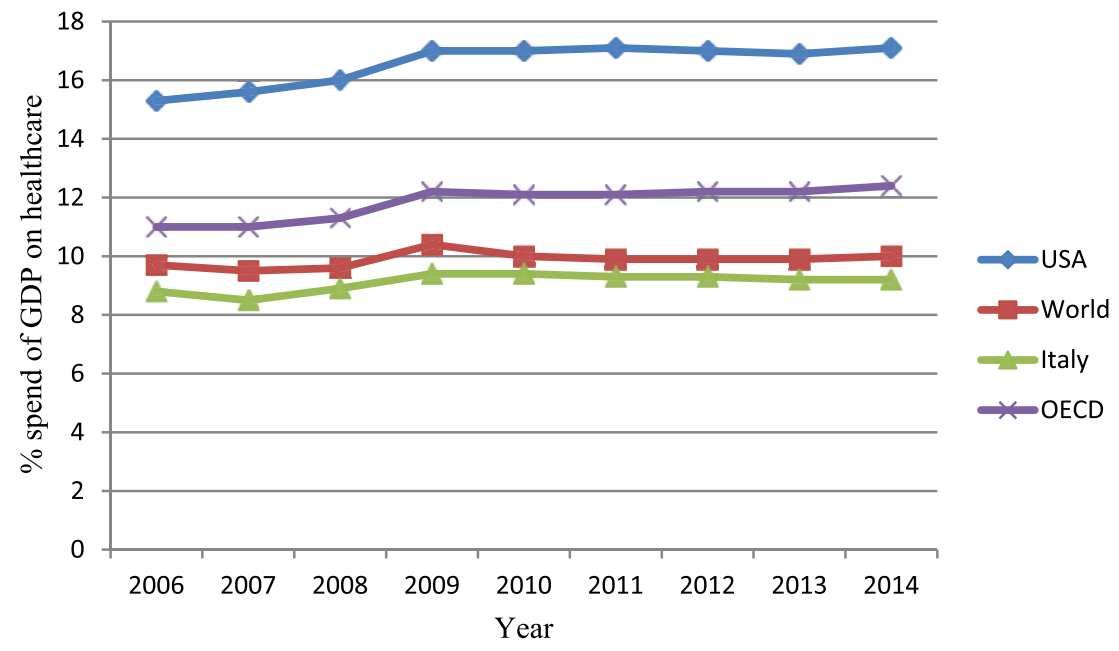

Figure 1. Comparison of percentages spend of GDP on healthcare in selected countries and globally (World Bank, 2016).

costs. Using data at the country level, it specifically set out to examine whether there was a relationship between the income levels of countries and their healthcare expenditure, and HCW generation rates. Second, using a case-study approach of a hospital from Italy, it also sought to understand the nature of the HCW generation patterns and the associated waste management costs.

\section{Factors affecting the generation of HCW}

The determination of factors, such as the sources, composition and generation patterns of the $\mathrm{HCW}$, is crucial to understanding how best to manage the associated costs and risks (Askarian et al., 2010; Voudrias et al., 2012).

Liberti et al. (1996) found that the majority of hazardous HCW arose from short-term patients in rehabilitation service $(52 \%)$, with analytical laboratories (23\%), and surgeries (14\%), being the next highest. While Cheng et al. (2009) noted that dialysis (23\%), the intensive care unit (17\%) and emergency care unit and outpatients ( $12 \%$ each), were the highest producers of HCW.

HCW generation patterns have been shown to be dependent on various factors, including department type and levels of patient activity (Da Silva et al., 2005; Moreira and Günther, 2013; Ozbek and Sanin, 2004; Tudor, 2007), GDP and healthcare spend per capita (Windfeld and Brooks, 2015), and diagnosis-related group (that is a measure of classification based on the principal and secondary diagnoses, patient characteristics and the procedures performed) (Mathausera and Wittenbecherb, 2013; Xin, 2015).

Measurement of waste generation rates from healthcare facilities is generally based on kilograms per bed per day $\left(\mathrm{kg} \mathrm{bed}^{-1}\right.$ day $^{-}$ 1) (Bazrafshan and Kord Mostafapoor, 2011; Bdour et al., 2007; Caniato et al., 2015; Cheng et al., 2009; Farzadkia et al., 2009). However, other units include kilograms per day $\left(\mathrm{kgday}^{-1}\right)$ (Moreira and Günther, 2013), kilogram per clinical performance (kg clinical performance ${ }^{-1}$ ) (Moreira and Günther, 2013) and kilogram per month per person $\left(\mathrm{kg} \mathrm{month}^{-1}\right.$ person $\left.^{-1}\right)$ (Tudor, 2007). Table 1 demonstrates the variation in hazardous HCW generation rates across selected countries.
Data on the costs associated with managing HCW are limited, primarily owing to commercial sensitivity. However, Windfield and Brooks (2015) report a rate of around \$US741 $\mathrm{t}^{-1}$ in the USA, and Komilis et al. (2011) state costs of $\$ U S 1800 t^{-1}$ for incineration and \$US1165 $\mathrm{t}^{-1}$ for sterilisation, in Greece. Alagöz and Kocasoy (2008) note that the collection and transport of the waste can constitute around $80 \%-95 \%$ of expenditure.

In Europe, the classification of $\mathrm{HCW}$ is based on the European Waste Catalogue (EWC) (EC, 2008). According to the EWC, codes specific for HCW start with the number 18. There are several different sub-categories, which can be hazardous (marked with an asterisk) or non-hazardous (EC, 2008). Table 2 provides examples of common $\mathrm{HCW}$ and their EWC classifications.

According to the Italian legislative decree DLgs. 152/2006, as amended by the DLgs. 205/2010, the first objective of effective HCW management is the protection of the health of patients, operators and all people involved (Italian Government, 2010). The legislation explicitly includes the safeguarding of the environment and the reduction of wastefulness as essential recommendations that operators should follow. Indeed, there is a focus on ensuring that the most efficient and cost-effective waste treatment should be chosen, favouring reduction, recovery and recycling of materials (APAT, 2008; ISPRA, 2014; Testa et al., 2012).

\section{Methods}

\section{GDP and healthcare spend per capita rates}

In order to determine the healthcare expenditure per capita, the GDP per capita and the percentage spend on healthcare were first sourced from World Bank (2016) for 2014 (as this was the year of the study). The choice of the countries was based on the availability of data. The World Bank was used as it is a credible and publicly available source of comparable global data. Based on Windfeld and Brooks (2015), the healthcare spend per capita 
Table 1. Comparison of hazardous HCW generation rates in selected countries.

\begin{tabular}{lll}
\hline Country & Hazardous healthcare waste $\left(\mathrm{kg} \mathrm{bed}^{-1} \mathrm{day}^{-1}\right)$ & Reference \\
\hline South Africa & 1.24 & UNEP (2012) \\
United States & 2.79 & UNEP (2012) \\
France & 4.8 & EC (2016) \\
Italy & 2.4 & EC (2016) \\
Taiwan & 0.6 & Cheng et al. (2009) \\
Korea (Rep) & $0.14-0.49$ & Jang et al. (2006) \\
Jordan & 0.61 & Abdulla et al. (2008) \\
Turkey & 0.63 & Birpinar et al. (2009) \\
Bulgaria & 0.4 & Spasov (2003) \\
Iran & $0.4-1.9$ & Taghipour and Mosaferi (2009) \\
Vietnam & 0.3 & UNEP (2012) \\
Bangladesh & 0.25 & Patwary et al. (2009a, 2009b) \\
Germany & 0.06 & EC (2016) \\
Tanzania & 0.08 & UNEP (2012) \\
\hline
\end{tabular}

Table 2. Classifications of some common HCW ladapted from EC, 2008).

\begin{tabular}{lll}
\hline Waste type & Waste status & EWC code \\
\hline Healthcare waste not contaminated with bodily fluids (e.g. masks, & Non-hazardous & 180104 \\
gowns and gloves), and sterilised laboratory waste & & \\
Plaster and similar wastes (e.g. from fracture clinics) & Non-hazardous & 180104 \\
Cytotoxic and cytostatic medicines & Hazardous & 180108 \\
Other medicines & Non-hazardous & 180109 \\
Potentially infectious waste - Anatomical waste & Hazardous & 180103 \\
Hazardous chemicals & Hazardous & 180106 \\
Other chemicals & Non-hazardous & 180107 \\
\hline
\end{tabular}

GDP was calculated by taking the percentage GDP spent on healthcare and multiplying this value by the per capita GDP.

The value for the healthcare expenditure per capita was then used as a proxy for 'wealth', to determine whether there was a link between the wealth of the country and generation rates of HCW. For Korea (Rep) and Iran, the average of the range reported in Table 1 was used for the waste generation rates.

The Spearman rank correlation test was used to measure the statistical relation between healthcare spend per GDP and hazardous HCW arisings.

\section{Waste generation rates}

A hospital in Italy was used as the case study site. The hospital is a public healthcare facility located in the Lombardy region. It is the largest hospital in the region, and at the time of the study had 933 beds. The study was undertaken during 2014.

Based in part on Tudor (2007), the quantity of non-hazardous $\mathrm{HCW}$ produced by the hospital was determined by analysing the records of the local company in charge of waste collection and disposal. The data for a 2-year period (2013-2014) were collected from the records. These data were used to calculate the monthly average waste production $\left(\mathrm{kgmonth}^{-1}\right)$, the monthly average waste production for each fraction $\left(\mathrm{kg} \mathrm{month}^{-1}\right)$ and average waste separation ratio $(\%)$.
Similarly to the non-hazardous HCW, the total quantity of hazardous HCW produced by the hospital was collected by analysing the records of the company that collected the waste. These data were then crosschecked with the quantity of waste produced by each hospital department. This provided the monthly total number of hospitalisation days (major clinical procedures), the day-hospital activities (minor clinical procedure) and the monthly number of occupied beds. The Management Control Office at the hospital provided the monthly number of clinical performances carried out by the hospital. The analysis involved a determination of the:

- hospital department's specific HCW production for 2013 and $2014\left(\mathrm{~kg} \mathrm{y}^{-1}\right)$;

- monthly HCW generation per hospitalisation for 2013 and $2014\left(\mathrm{~kg} \mathrm{day}^{-1}\right)$ per hospital ward;

- monthly HCW production per clinical procedure for 2013 and $2014\left(\mathrm{~kg}\right.$ procedure $\left.^{-1}\right)$ per hospital ward;

- daily HCW production per occupied bed during 2013-2014 $\left(\mathrm{kg} \mathrm{day}^{-1}\right.$ bed $\left.^{-1}\right)$ per hospital ward.

Generation rates for 180103 (hazardous HCW), were correlated with the number of: (1) days patients stayed in the hospital, which included the ordinary hospitalisation days and day-hospital activities; (2) clinical procedures (i.e. specialist visits, laboratory analyses and rehabilitation therapies); and (3) occupied beds for each 
Table 3. Healthcare expenditure per capita GDP (World Bank, 2016).

\begin{tabular}{|c|c|c|c|}
\hline Country & $\begin{array}{l}\text { Health expenditure as a } \\
\text { percentage of GDP (\%GDP) } \\
\text { (a) }\end{array}$ & $\begin{array}{l}\text { Per capita GDP } \\
\text { (\$USy-1) } \\
\text { (b) }\end{array}$ & $\begin{array}{l}\text { Health expenditure per } \\
\text { capita GDP }\left(\$ \cup S y^{-1}\right) \\
(a \times b)\end{array}$ \\
\hline Bangladesh & 2.8 & 1087 & 30.44 \\
\hline Bulgaria & 8.4 & 7851 & 659.48 \\
\hline France & 11.5 & 42,726 & 4913.49 \\
\hline Germany & 11.3 & 47,774 & 5398.46 \\
\hline Iran & 6.9 & 5443 & 375.57 \\
\hline Italy & 9.2 & 35,223 & 3240.52 \\
\hline Jordan & 7.5 & 5443 & 408.23 \\
\hline Korea (Rep) & 7.2 & 27,971 & 2013.91 \\
\hline South Africa & 8.8 & 6484 & 570.59 \\
\hline Tanzania & 5.6 & 955 & 53.48 \\
\hline Turkey & 5.4 & 10,515 & 567.81 \\
\hline United States & 17.1 & 54,630 & 9341.73 \\
\hline Vietnam & 7.1 & 2052 & 145.69 \\
\hline
\end{tabular}

GDP: gross domestic product.

considered hospital ward. Occupied bed refers to patients who underwent a simple surgical intervention that required spending at least 1 day in bed, excluding day-hospital procedures. Therefore, for the calculation only, the hazardous HCW produced during the stay was considered because of a major clinical procedure.

\section{Waste management costs}

The costs were calculated for 2014 only, owing to the hospital moving from the old building to the new one, which did not allow data collection for 2013. All the economic data were collected by reviewing the hospital's official payment documents and receipts. In addition, informal interviews were held with technical staff and directors to fill any gaps in the data. The analyses were focused on the:

- HCW disposal costs;

- non-hazardous HCW fee (the hospital paid a yearly fee which was dependent on the area occupied by the department, rather than the quantity of waste produced);

- internal depot management and internal waste transportation costs;

- operations and maintenance cost of the waste transportation remote control system.

The sum of all these costs enabled the calculation of the overall waste management costs. This overall cost was shared between the two waste streams based on the functioning of the internal waste management system. The hospital used a remote-control transportation system and the internal waste depot for all its waste. It had a centralised and remote-controlled transportation system for all waste produced, which were temporarily stored at the internal waste depot, before their transport to the final disposal treatment/site. The type of waste management system employed at the site did not allow for systematic division of all the costs according to the different types of treated waste. In particular, the common cost for the non-hazardous and hazardous
HCW referred to the internal waste depot management, internal goods transportation and the remote-control system for waste and good transportation running, and management costs. The internal depot management and internal waste transportation costs were shared as $30 \%$ for the non-hazardous HCW and $70 \%$ for the hazardous HCW, as the Halipack ${ }^{\circledR}$ bins had a higher cost when compared with the plastic bags used for the non-hazardous HCW. Moreover, each Halipack ${ }^{\circledR}$ was weighed when it arrived at the internal waste depot. In order to determine the overall costs' split, the running and management costs for the waste remote transportation system was shared between the hazardous and non-hazardous HCW as $60.3 \%$ and $39.7 \%$, respectively. The percentages were calculated based on the average number of trips carried out by the remote-control system during a typical working day, which were 494 trips every day, 196 (39.7\%) trips for the nonhazardous HCW and 298 (60.3\%) trips for the hazardous HCW.

\section{Results}

\section{Healthcare expenditure per GDP and waste arising}

Table 3 suggests that generally the more developed countries (USA, Germany, France, Italy) had a higher per capita health expenditure.

Figure 2 illustrates a positive correlation between healthcare spend per GDP and hazardous HCW arisings $(0.746, p<0.05)$. This trend is particularly true for the USA. Most countries fell within the range. In Germany, waste generation rates fell well below the trend, while France, and to a lesser extent Italy, produced more waste than expected.

\section{Waste generation rates}

The monthly average non-hazardous HCW production for the period 2013-2014 was primarily comprised of unsorted municipal waste $\left(71.4 \mathrm{tmonth}^{-1}\right)$, organic waste $\left(14.4 \mathrm{tmonth}^{-1}\right)$ and paper/ 


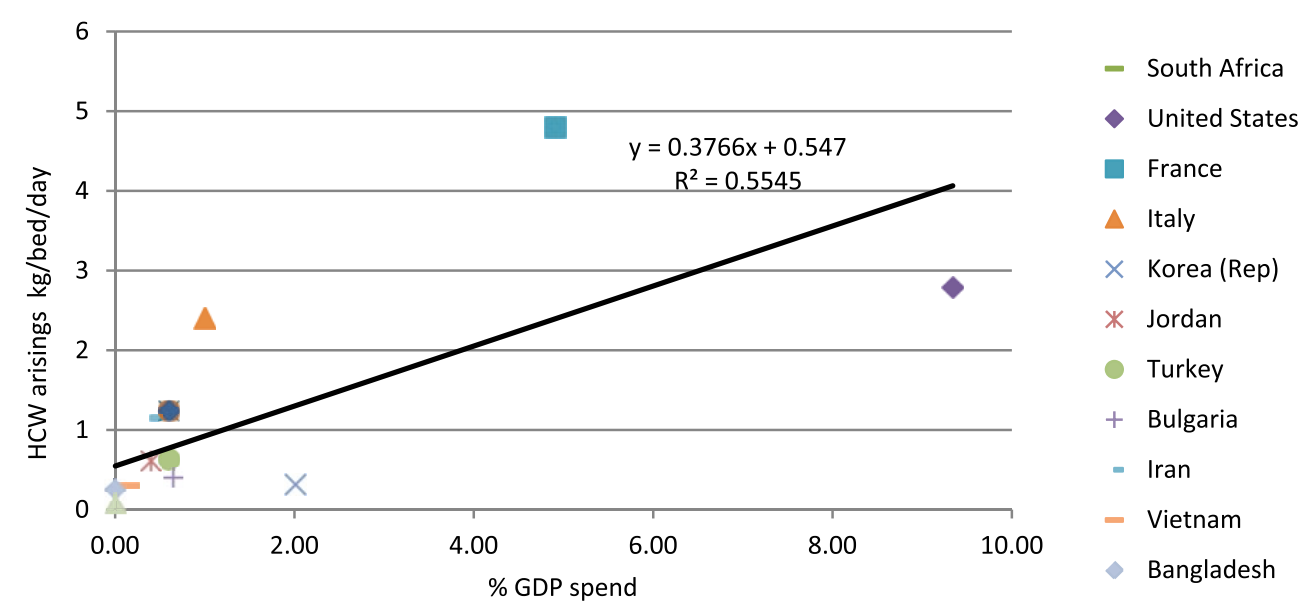

Figure 2. Correlation between healthcare spend as a percentage of GDP (World Bank, 2016) and hazardous HCW arisings.

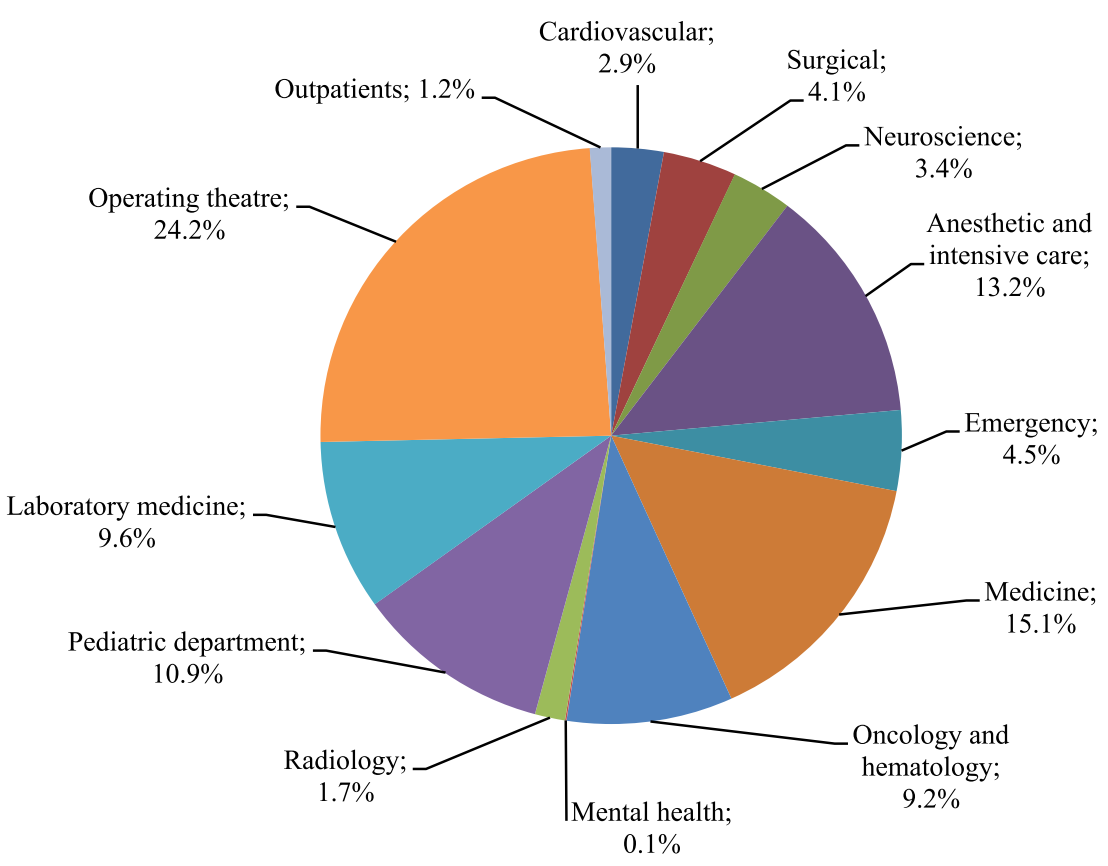

Figure 3. Production of 180103 waste for each hospital department during 2013-2014.

cardboard (12.76 $\left.\mathrm{tmonth}^{-1}\right)$. The average waste segregation ratio for non-hazardous $\mathrm{HCW}$ was $34.3 \%$.

The main type of hazardous HCW produced was infectious (180103), with a total waste production of $1279 \mathrm{t}$ and an average monthly rate of $53.3 \mathrm{t}$. Figure 3 illustrates that the main sources of 180103 waste for 2013-2014 were the operating theatre, followed by the medicine department (which included the nephrology, haematology and gastroenterology wards), anaesthetic and intensive care, and paediatrics.

As shown in Figure 4, the average monthly HCW production and number of hospitalisation days for the period were $25.36 \mathrm{t}$ and 25,032 days, respectively. Thus, the average per capita waste production rate was $1.01 \mathrm{~kg}^{-1 a y}{ }^{-1}$.

The departments with the highest average monthly average waste generation per hospitalisation day were anaesthetic and intensive care $3\left(6.57 \mathrm{~kg} \mathrm{day}^{-1}\right)$, anaesthetic and intensive care 2 $\left(4.57 \mathrm{~kg} \mathrm{day}^{-1}\right)$ and paediatric and intensive care $\left(3.45 \mathrm{~kg} \mathrm{day}^{-1}\right)$.
Figure 5 illustrates that the monthly average HCW production and number of clinical procedures for the period 2013 2014 were $14.35 \mathrm{t}$ and 290,676 procedures, respectively. Thus, the average monthly $\mathrm{HCW}$ production per procedure was $0.046 \mathrm{~kg}$ clinical procedure ${ }^{-1}$. The monthly number of procedures fluctuated, nevertheless the number of procedures fell during August for both years owing to the Italian summer holiday period.

The departments with the highest average monthly waste generation rates per clinical procedure were radiology $(0.67 \mathrm{~kg}$ procedure $\left.^{-1}\right)$, gastroenterology-digestive endoscopy $\left(0.50 \mathrm{~kg}_{\text {procedure }}{ }^{-1}\right)$ and plastic surgery $\left(0.44 \mathrm{~kg}\right.$ procedure $\left.{ }^{-1}\right)$.

The hospital had an average occupation ratio of $82.4 \%$, therefore the average daily HCW generation per activated bed and per occupied bed rates were $0.9 \mathrm{~kg}$ and $1.09 \mathrm{~kg}$, respectively. The highest generating departments of hazardous HCW per daily occupied bed were anaesthetics $3\left(5.96 \mathrm{~kg} \mathrm{day}^{-1}\right.$ bed $\left.^{-1}\right)$, anaesthetics $2\left(4.3 \mathrm{~kg} \mathrm{day}^{-1}\right.$ bed $\left.^{-1}\right)$, 


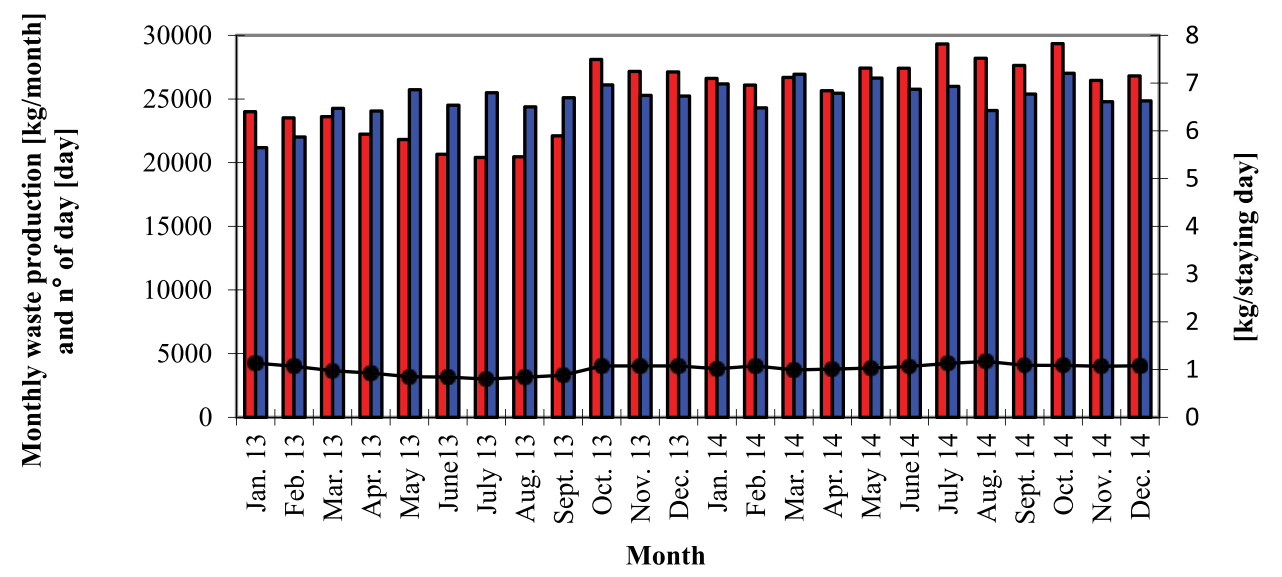

$\square$ Production of $180103 *[\mathrm{Kg}] \quad$ Hospitalization days and day hospital [d] Production of $180103 *[\mathrm{~kg} / \mathrm{d}]$

Figure 4. Generation of 180103 waste and the number of hospital days.

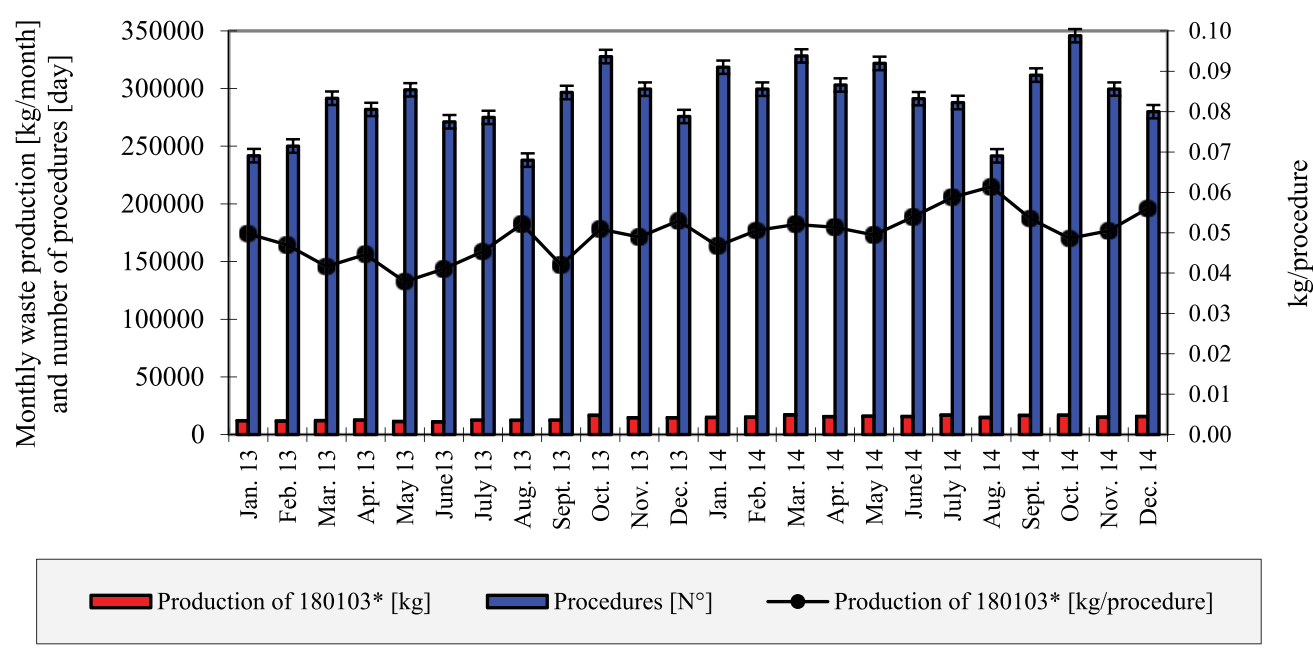

Figure 5. Link between the 180103 waste produced and the number of clinical procedures.

paediatric and intensive care $\left(3.37 \mathrm{~kg}^{-1} \mathrm{day}^{-1}\right.$ bed $)$ and gastroenterology 2 - digestive endoscopy $\left(3.09 \mathrm{~kg} \mathrm{day}^{-1} \mathrm{bed}^{-1}\right)$.

\section{Waste management costs}

The overall annual costs of disposing of the wastes (i.e. waste collection and transportation from the internal waste depot to the final treatment plant, for example incineration plants for 180103 and wastewater treatment plants for liquid hazardous waste operated by a private enterprise), was \$US2,274,980 (i.e. $€ 1,710,897$ since the average rate of exchange in 2014 was $1.3297 € \$$ US $^{-1}$; Board of Governors of the Federal Reserve System, 2017). Of these costs, that for 180103 was highest at \$US1,604,085, while \$US661,770 were spent to dispose $263.5 \mathrm{t}$ of 180106 (i.e. chemicals consisting of or containing hazardous substances).

The site paid a yearly national fee (called TARI) for the nonhazardous HCW of \$US704,051, which was based on the physical space occupied and not the quantity of waste produced. The overall costs of the internal depot management, Halipack ${ }^{\circledR}$ and bags furniture, as well as the internal waste transportation were \$US1,087,397 per year and \$US629,039 per year, respectively. While the operating and maintenance costs for the remotecontrolled waste transportation system were $\$$ US284,485 per year and \$US99,240 per year, respectively. Table 4 outlines that the overall waste management costs in 2014 were \$US5,079,191, or approximately $\$ \mathrm{US} 2.36 \mathrm{~kg}^{-1}$.

Table 5 lists that the overall unit costs for the non-hazardous $\mathrm{HCW}$ and hazardous $\mathrm{HCW}$ were approximately $\$ \mathrm{US} 1.14 \mathrm{~kg}^{-1}$ and \$US3.93 $\mathrm{kg}^{-1}$, respectively.

\section{Discussion}

Generally, more developed countries had a higher per capita health spend (Table 3). Similar to Winfeld and Brooks (2015), GDP and the percentage spend on healthcare correlated positively with $\mathrm{HCW}$ generation rates at the national level. Thus generally, higher income countries that spent more on healthcare provision also produced more waste. This is instructive, as it suggests that given that spend on healthcare provision is 
Table 4. Overall waste management costs in 2014.

Item cost

Final cost $(+22 \%$ VAT) (\$US $\mathrm{y}^{-1}$ )

Healthcare waste disposal cost

$2,274,980$

Non-hazardous HCW cost

704,051

Internal depot management and internal goods transportation

$1,716,435$

Remote control system for waste and good transportation running and management costs

383,725

Total

$5,079,191$

HCW: healthcare waste.

Table 5. Overall unit waste management costs for the two waste streams in 2014.

\begin{tabular}{|c|c|c|c|}
\hline Item cost & Unit & Non-hazardous HCW & Hazardous HCW \\
\hline Managing the internal depot, Halipack ${ }^{\circledR}$ bags and used furniture & $\$ \cup S y^{-1}$ & 326,219 & 761,177 \\
\hline Internal goods transportation & $\$ \cup S y^{-1}$ & 188,711 & 440,327 \\
\hline Remote control transportation system and lift & \$USy-1 & 112,873 & 171,612 \\
\hline Operating and management & $\$ U_{S} y^{-1}$ & 39,398 & 59,842 \\
\hline Non-hazardous HCW costs & $\$ \cup S y^{-1}$ & 704,051 & - \\
\hline Hazardous HCW costs & $\$ \cup S y^{-1}$ & - & $2,274,980$ \\
\hline Total costs & \$USy-1 & $1,371,252$ & $3,707,939$ \\
\hline Waste amount & $\mathrm{kg}$ & $1,206,136$ & 944,611 \\
\hline Unit costs & $\$ U S k^{-1}$ & 1.14 & 3.93 \\
\hline
\end{tabular}

HCW: healthcare waste.

rising, waste quantities will also rise. It also indicates the urgent need for higher income countries to do more as it relates to decoupling spend and waste generation rates and recovery value from that produced. An important point to note though is that there were exceptions to the general rule. For example, Germany, despite its high GDP, had a significantly lower rate compared with the other countries that spent a 'high' percentage of their GDP on healthcare, while France and Italy were above the expected levels (Figure 2). These deviations from the expectations may have been owing to various reasons, including more stringent enforcement of regulations and greater efficiency in processes. However, based on the findings from the site, a key factor may relate to levels of waste segregation. The non-hazardous waste contained high levels of potentially recyclable waste. While the hazardous waste was not examined, it is possible that there may have been a significant percentage of this waste that was not hazardous. Higher quantities of hazardous waste cost more, as unit prices were higher (Table 5). This assumption would however, require further study both in Italy, as well as in France. However, greater segregation of hazardous and non-hazardous waste could lead to significant cost reductions (Royal College of Nursing, 2011).

At the site level, the average per capita $\mathrm{HCW}$ generation was $1.01 \mathrm{~kg} \mathrm{day}^{-1}$, which is around half of the national average (Table 1). Anaesthetics and the intensive care department were the highest average monthly generators of hazardous infectious HCW (i.e. 180103). The average monthly 180103 production rate/clinical procedure was $0.046 \mathrm{~kg}$ clinical procedure ${ }^{-1}$, with the highest generating departments being radiology and gastroenterology. This waste generation rate/procedure is about 2.5 times that of Moreira and Günther (2013). If generation rates are examined on the basis of bed occupancy, then the average daily waste production per activated bed, and per occupied bed were $0.9 \mathrm{~kg}$ and $1.09 \mathrm{~kg}$, respectively, with anaesthetics and paediatric and intensive care being among the highest producers. The production of higher quantities of waste from 'shortstay' clinical areas is similar to the findings of others (e.g. Cheng et al., 2009; Liberti et al., 1996). The strong link between waste generation and both department type (Moreira and Günther, 2013; Tudor, 2007), as well as clinical procedure (Mathausera and Wittenbecherb, 2013; Xin, 2015), is also similar to other studies. The rate for per occupied bed waste arisings is about a third that of the USA, and slightly lower than that of South Africa (UNEP, 2012).

As shown in Table 4, the overall costs of managing the waste during 2014 were $\$ U S 5,079,191$, at a unit cost of \$US2.36 kg-1. Disposal costs accounted for approximately $44.8 \%$ of these overall costs, at $\$ U S 2,274,980$. While the costs for managing the internal depot, Halipack ${ }^{\circledR}$ bins and the internal waste transportation were approximately $21.4 \%$ and $12.4 \%$, respectively. As expected, the management of $\mathrm{HCW}$ was much higher than that of the non-hazardous waste, at a unit cost of \$US3.93 $\mathrm{kg}^{-1}$, as compared with \$US1.14 $\mathrm{kg}^{-1}$. In addition, the hospital also paid a fee (TARI) of \$US704,051 for the management of its non-hazardous waste. However, as the costs for the management of this waste were linked to the physical space occupied rather than the quantity generated may explain the rise in waste following the move to the new site. Evidently, while the legislation exists in Italy (DLgs.152/2006), the practice on the ground does not always take account of the need to 
employ efficient and cost-effective processes. Therefore, it is suggested that the TARI should take account also of the quantity of waste produced, in addition to the physical area occupied, in order to serve as a more effective incentive for waste reduction (Mühlich et al., 2003).

There were some limitations to the study. First, the data for the costing were taken from a range of sources, and years, as it was not possible to source the data from one reference. This might have introduced some biased into the data. However, the process for managing the data was the same. Second, the choice of countries selected was based solely on the availability of data. Nevertheless, they represent a range of GDPs. Third, the study focused only on one site. However, this was compensated for by the detail provided by the site, which can often be a challenge. Nevertheless, the inclusion of a wider range of sites and countries would help to ensure greater validity and reliability of the data and conclusions.

\section{Conclusions}

With increasing spend on healthcare, there is an increasing focus on a more sustainable approach to managing $\mathrm{HCW}$ generation and the associated costs. This study has illustrated that there is a positive correlation between healthcare spend and waste arisings, with higher income countries generally producing more waste. Evidently, however, as illustrated by Germany, spend and waste arisings can be decoupled. In Italy, greater reduction could potentially also be facilitated through attention being paid to linking the TARI to waste generation rates. The site level findings suggest that factors such as department type, clinical procedure, and potentially also waste segregation levels, are key issues that should be focused upon. In addition, given the high percentage of both unsorted and organic materials in the non-hazardous waste, use of more sustainable methods (e.g. biological treatment), would serve to reduce the disposal costs. It is only by addressing these issues that waste arisings and spend might most effectively be decoupled and reduced.

\section{Acknowledgements}

The authors are grateful to the Hospital and its staff for providing data and hosting the study. Acknowledgements are especially given to Fabio Nodari for his support during data collection.

\section{Author contributions}

Mentore Vaccari set up the research and with Terry Tudor carried out the literature survey, data analysis, results discussion and article drafting. Andrea Perteghella contributed to the data analysis and article drafting.

\section{Declaration of conflicting interests}

The authors declared no potential conflicts of interest with respect to the research, authorship, and/or publication of this article.

\section{Funding}

The authors received no financial support for the research, authorship, and/or publication of this article.

\section{References}

Abdulla F, Qdais HA and Rabi A (2008) Site investigation on medical waste management practises in Northern Jordan. Waste Management 28: $450-458$.

Alagöz AZ and Kocasoy G (2008) Improvement and modification of the routing system for the health-care waste collection and transportation in Istanbul. Waste Management 28: 1461-1471.

APAT (2008) Valutazioni quali-quantitative sulla produzione e gestione dei rifiuti speciali sanitari. Roma: APAT Rapporti Tecnici.

Askarian M, Heidarpoor P and Assadian O (2010) A total quality management approach to healthcare waste management in Namazi Hospital, Iran. Waste Management 30: 2321-2326.

Bazrafshan E and Kord Mostafapoor F (2011) Survey of medical waste characterization and management in Iran: A case study of Sistan and Baluchestan Province. Waste Manage \& Research 29: 442-450.

Bdour A, Altrabheh B, Hadadin N, et al. (2007) Assessment of medical wastes management practice: A case study of the northern part of Jordan. Waste Management 27: 746-759.

Birpinar ME, Bilgili MS and Erdoğan T (2009) Medical waste management in Turkey: A case study of Istanbul. Waste Management 29: 445-448.

Board of Governors of the Federal Reserve System (2017) Foreign Exchange Rates - G.5A Annual. Available at: https://www.federalreserve.gov/ releases/g5a/current/ (accessed 20 April 2017).

Campion N, Thiel CL, Woods NC, et al. (2015) Sustainable healthcare and environmental life-cycle impacts of disposable supplies: A focus on disposable custom packs. Journal of Cleaner Production 94: 46-55.

Caniato M, Tudor TL and Vaccari M (2015) International governance structures for health-care waste management: A systematic review of scientific literature. Journal of Environmental Management 153: 93-107.

Castellani V, Sala S and Mirabella N (2015) Beyond the throwaway society: A life cycle-based assessment of the environmental benefit of reuse. Integrated Environmental Assessment and Management 11: 373-382.

Cheng YW, Sung FC, Yang Y, et al. (2009) Medical waste production at hospitals and associated factors. Waste Management 29: 440-444.

Da Silva CE, Hoppe AE, Ravanello MM, et al. (2005) Medical wastes management in the south of Brazil. Waste Management 25: 600-605.

EC (2008) EU waste legislation. Available at: http://ec.europa.eu/environment/waste/legislation/a.htm (accessed 22 April 2017).

EC (2016) Eurostat: Environmental data centre on waste. Available at: http:// ec.europa.eu/eurostat/web/waste/overview (accessed 24 April 2017).

Farzadkia M, Moradi A and Shah Mohammadi M (2009) Hospital waste management status in Iran: A case study in the teaching hospitals of Iran University of Medical Sciences. Waste Manage and Research 27: 384-389.

Ibbotson S, Dettmer T, Kara S, et al. (2013) Eco-efficiency of disposable and reusable surgical instruments - A scissors case. International Journal of Life Cycle Assessment 18: 1137-1148.

ISPRA (2014) Rapporto Rifiuti Speciali - Edizione 2014. Available at: http:// www.isprambiente.gov.it/it/pubblicazioni/rapporti/rapporto-rifiuti-speciali-edizione-2014 (accessed 24 April 2017).

Italian Government (2010) Disposizioni di attuazione della direttiva 2008/98/ CE del Parlamento europeo e del Consiglio del 19 novembre 2008 relativa ai rifiuti e che abroga alcune direttive. D.lgs 205. G. U. n. 288 $10 / 12 / 2010$.

Jang YC, Lee C, Yoon OS, et al. (2006) Medical waste management in Korea. Journal of Environmental Management 80: 107-115.

Komilis D, Katsafaros N and Vassilopoulos P (2011) Hazardous medical waste generation in Greece: Case studies from medical facilities in Attica and from a small insular hospital. Waste Management and Research 29: 807-814.

Liberti L, Tursi A, Costantino N, et al. (1996) Optimization of infectious hospital waste management in Italy: part II. Waste characterization by origin. Waste Management and Research 14: 417-431.

Mathausera I and Wittenbecherb F (2013) Hospital payment system based on diagnosis related groups: experiences in low and middle income countries. World Health Organization Bulletin 91: 746A-756.

Moreira AMM and Günther WMR (2013) Assessment of medical waste management at a primary health-care center in São Paulo, Brazil. Waste Management 33: 162-167.

Mosquera M, Andrés-Prado MJ, Rodríguez-Caravaca G, et al. (2014) Evaluation of an education and training intervention to reduce health 
care waste in a tertiary hospital in Spain. American Journal of Infection Control 42: 894-897.

Mühlich M, Scherrer M and Daschner FD (2003) Comparison of infectious waste management in European hospitals. Journal of Hospital Infection 55: 260-268.

Nichols A, Grose J and Mukonoweshuro R (2016) Achieving cost and carbon savings in neonatal practice: A review of the literature on sustainable waste management. Journal of Neonatal Nursing 22: 81-87.

Ozbek M and Sanin FD (2004) A study of the dental solid waste produced in a school of dentistry in Turkey. Waste Management 24: 339-345.

Patwary MA, O'Hare WT, Street G, et al. (2009a) Quantitative assessment of medical waste generation in the capital city of Bangladesh. Waste Management 29: 2398-2403.

Patwary MA, O'Hare WT, Street G, et al. (2009b) Health and safety perspective on medical waste management in a developing country: A case study of Dhaka City. In: Nabhani F (ed) Proceedings of the 19th International FAIM Conference on Flexible Automation and Intelligent Manufacturing, University of Teesside, Middlesbrough, UK, 6-8 July 2009, pp. 282-290. Gemini International Limited.

Royal College of Nursing (2011) Freedom of information report on waste management. London. UK: Royal College of Nursing.

Spasov A (2003) Hospital waste management and health-ecological risk prophylaxis in Bulgaria. Florida State University, Sofia, Bulgaria.

Swensen SJ, Kaplan GS, Meyer GS, et al. (2011) Controlling healthcare costs by removing waste: What American doctors can do now. BMJ Quality and Safety 20: 534-537.
Taghipour H and Mosaferi M (2009) Characterization of medical waste from hospitals in Tabriz, Iran. Science of the Total Environment 407: 1527-1535.

Testa F, Iraldo F, Frey M, et al. (2012) What factors influence the uptake of GPP (green public procurement) practices? New evidence from an Italian survey. Ecological Economics 82: 88-96.

Tudor TL (2007) Towards the development of a standardised measurement unit for healthcare waste generation. Resources, Conservation and Recycling 50: 319-333.

UNEP (2012) Compendium of technologies for the treatment/destruction of healthcare waste. Osaka, Japan.

Viani C, Vaccari M and Tudor T (2016) Recovering value from used medical instruments: A case study of laryngoscopes in England and Italy. Resources, Conservation and Recycling 111: 1-9.

Voudrias E, Goudakou L, Kermenidou M, et al. (2012) Composition and production rate of pharmaceutical and chemical waste from Xanthi General Hospital in Greece. Waste Management 32: 1442-1452.

World Health Organization (2011) Waste from health-care activities. Geneva: World Health Organization.

World Health Organization (2014) Safe management of wastes from healthcare activities (2nd edn). Geneva: WHO Press.

Windfeld ES and Brooks MSL (2015) Medical waste management - A review. Journal of Environmental Management 163: 98-108.

World Bank (2016) Health expenditure total (\% of GDP) - 2016. Available at: http://data.worldbank.org/indicator/SH.XPD.TOTL.ZS (accessed 24 April 2017).

Xin Y (2015) Comparison of hospital medical waste generation rate based on diagnosis-related groups. Journal of Cleaner Production 100: 202-207. 